\title{
Aspirochlorine Class Compounds from Aspergillus flavus Inhibit Azole-Resistant Candida abicans
}

Paul Klausmeyer, ${ }^{\dagger}$ Thomas G. McCloud, ${ }^{*, \dagger}$ Kenneth D. Tucker, ${ }^{\ddagger, \S}$ John H. Car dellina $\Pi^{\perp}$ and Robert $\mathrm{H}$. Shoemaker ${ }^{\perp}$

${ }^{\dagger}$ Natural Products Support Group, SAIC-Frederick, Inc., Bldg 431, FCRDC, Frederick, MD 21702-1201; ${ }^{\ddagger \Sigma}$ Antimicrobial Research Sipport Group, SAIC-Frederick, Inc.; and ${ }^{\perp}$ Screening Technologies Branch, Developmental Therapeutics Program, Division of Cancer Treatment and Diagnosis, National Cancer Institute-Frederick, Frederick, Maryland 21702-1201

${ }^{5}$ Current Address: NBACC, 7435 New Technology Way, Frederick, Maryland 21703

\section{List of Supp orting Information}

Figure S1. ${ }^{1} \mathrm{H}$ NMR Spectrum (500 MHz) of Aspirochlorine (1) in $\mathrm{CD}_{2} \mathrm{Cl}_{2}$

Figure $\mathrm{S} 2 .{ }^{1} \mathrm{H} \mathrm{NMR}$ Spectrum (500 MHz) of Tetrathiospirochl orine (2) in $\mathrm{CD}_{2} \mathrm{Cl}_{2}$

Figure S3. ${ }^{1} \mathrm{H}$ NMR Spectrum $(500 \mathrm{MHz})$ of 3(S)-(1H-Indol-3-ylmethyl)-6(R)-isobutyl1-methyl-piperazine-2,5-dione (3)

(Cyclo(D-N-methylLeu-L-Trp)) (3) in $\mathrm{CD}_{3} \mathrm{OD}$

Figure S4. ${ }^{13} \mathrm{C}$ NMR Spectrum $(125 \mathrm{MHz})$ of $3(\mathrm{~S})-(1 / H$-Indol-3-ylmethyl $)-6(\mathrm{R})$-i sobutyl1-methyl-piperazine-2,5-dione (3)

(Cyclo(D- $N$-methylLeu-L-Trp)) (3) in $\mathrm{CD}_{3} \mathrm{OD}$

Figure S5. LRESMMS of Aspirochlorine (1), Trithioaspirochlorine (2), and

Tetrathioaspirochlorine (3) in MeCN-H2O (1:1) HPLC mobile phase 



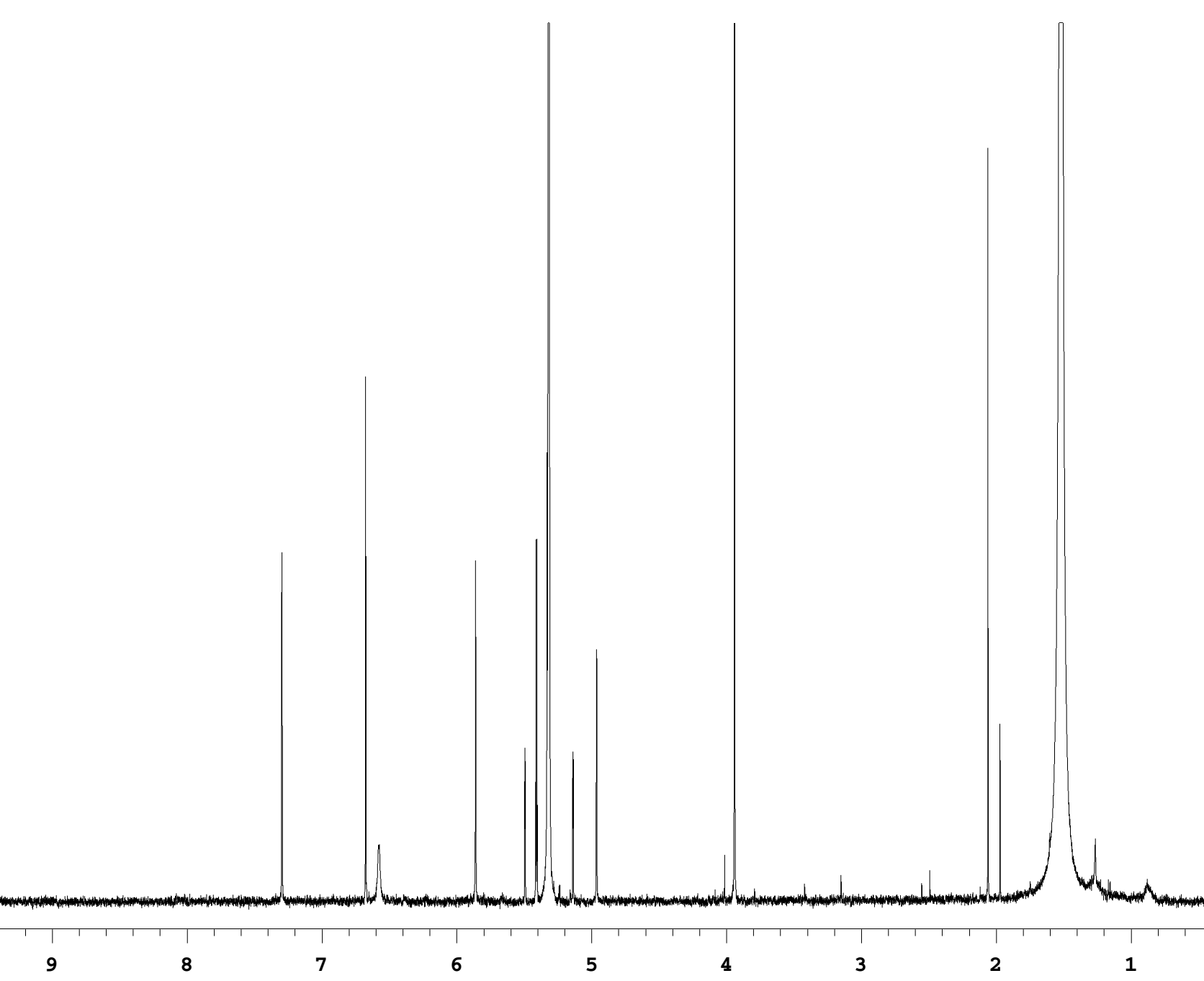

Figure S2. ${ }^{\mathrm{H}} \mathrm{NMR}$ Spectrum (500 MHz) of Tetrathiospirochlorine (2) in $\mathrm{CD}_{2} \mathrm{Cl}_{2}$ 


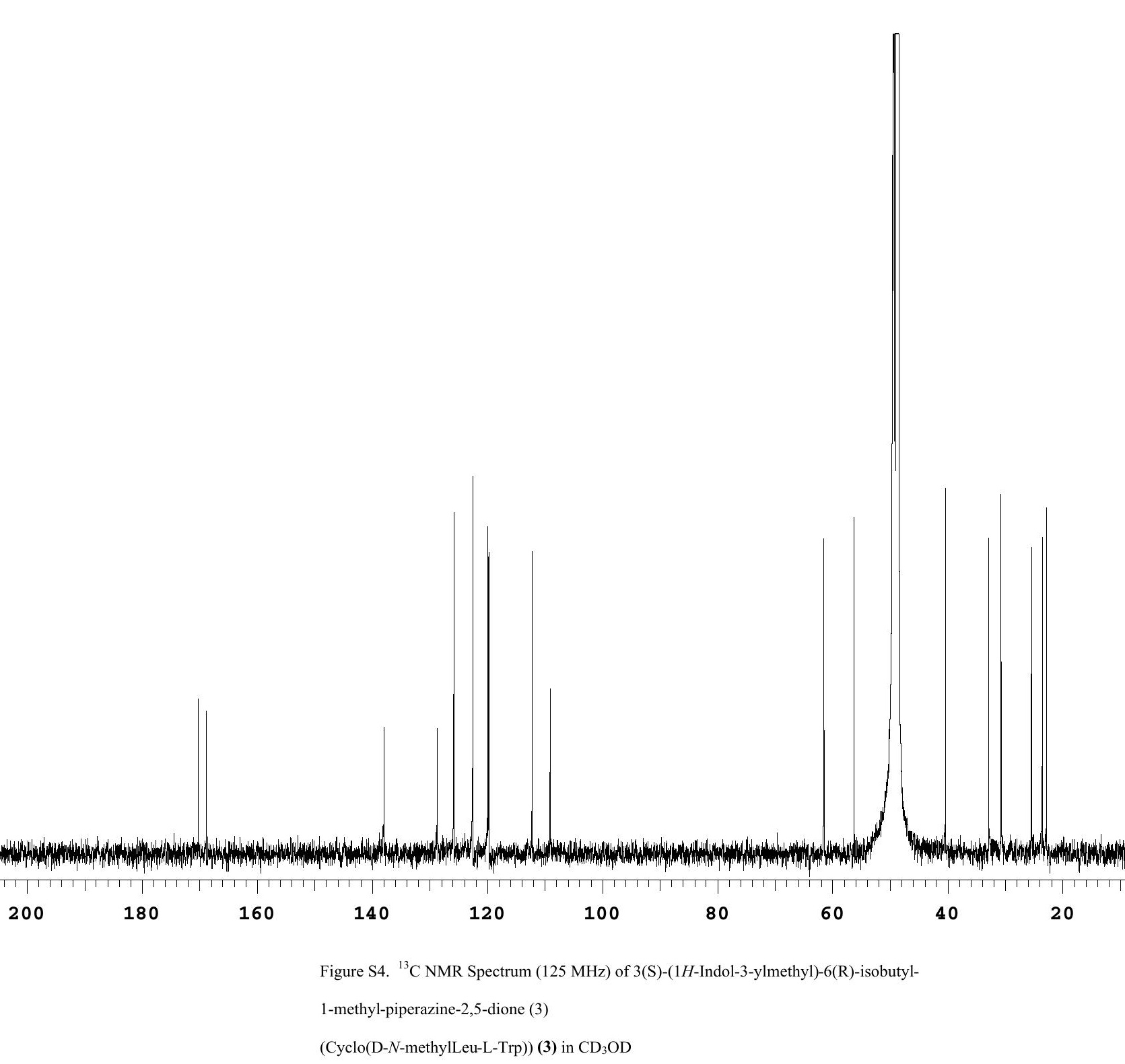




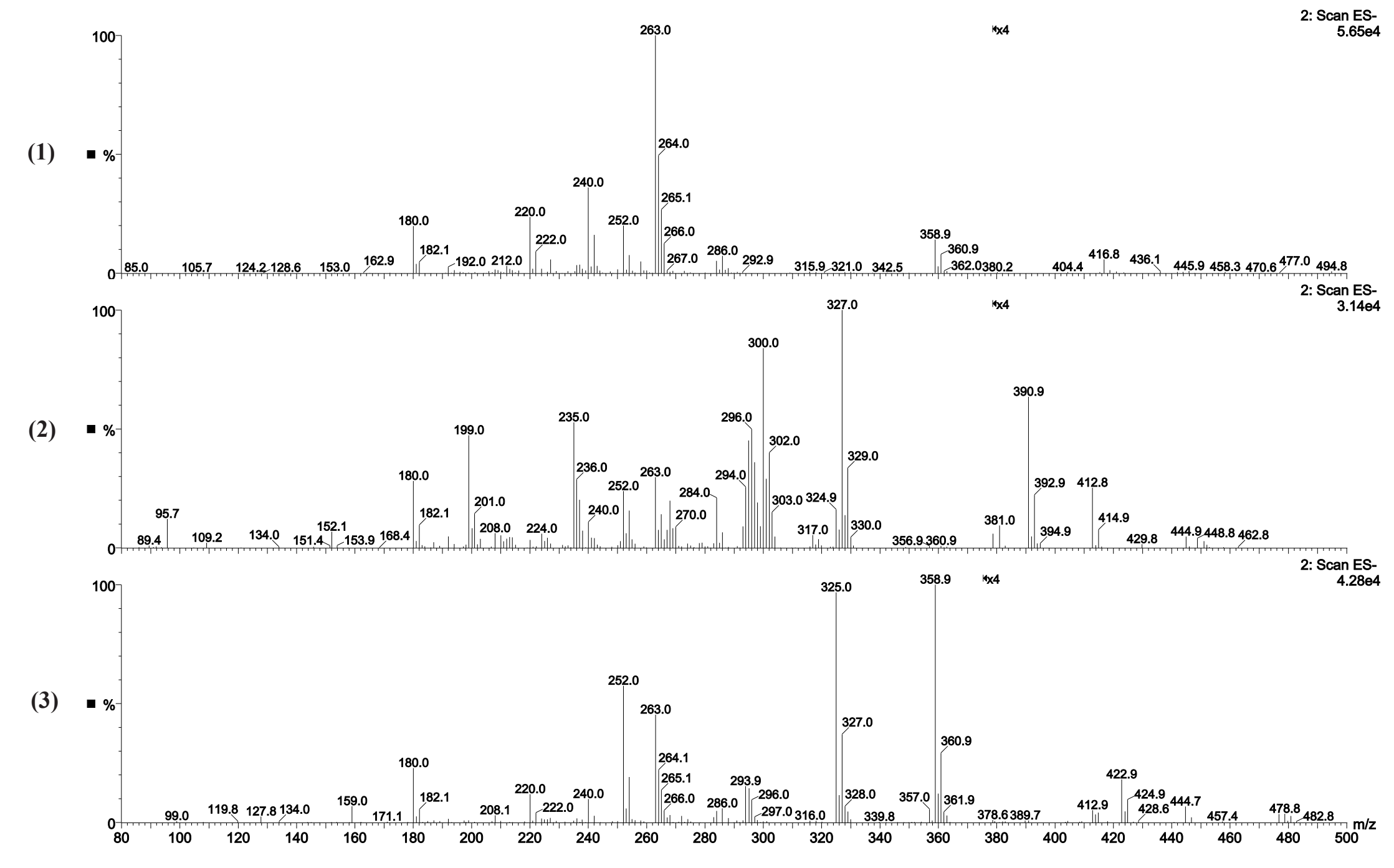

Figure S5. LRESIMS of Aspirochlorine (1), Trithioaspirochlorine (2), and Tetrathioaspirochlorine (3) in MeCN-H2O (1:1) HPLC mobile phase 